\title{
Effects of different treatments and other factors on the prognosis of patients with ewing sarcoma
}

\author{
Kunchi Hua, Yongcheng Hu \\ Department of Orthopedic Oncology, Tianjin Hospital, Tianjin 300211, China \\ Contributions: (I) Conception and design: KC Hua; (II) Administrative support: YC Hu; (III) Provision of study materials or patients: KC Hua; (IV) \\ Collection and assembly of data: KC Hua; (V) Data analysis and interpretation: KC Hua; (VI) Manuscript writing: All authors; (VII) Final approval \\ of manuscript: All authors. \\ Correspondence to: Yongcheng Hu. Department of Orthopedic Oncology, Tianjin Hospital, Tianjin 300211, China. Email: HuYC62@163.com.
}

Background: Ewing sarcoma is a small round cell tumor of bone or soft tissue originating from the neuroectoderm. Aggressive and highly malignant are the main pathological features of the tumor. Studying the effects of different treatments and other factors on prognosis will help us to understand the disease more deeply and find a way to actively deal with it.

Methods: Through the search of the National Cancer Institute database, ewing sarcoma patients registered between January 1, 2004 and December 31, 2015 were selected as research goals. Summarize the basic information of patients included in the study, including demographics, tumor pathology and treatment. Kaplan-Meier survival curves and log-rank test were used to analyze the overall survival (OS) and ewing sarcoma-specific survival (ESSS) of each prognostic factor and categorical variable. Multivariate Cox regression analysis was used to analyze all-cause mortality (ACM) and ewing sarcoma-specific mortality (ESSM) for each prognostic factor and categorical variable.

Results: A total of 837 ewing sarcoma patients were included in this article. Patients receiving chemotherapy (CT), radiotherapy (RT) or surgery were 804 (96.1\%), 414 (49.5\%), and 524 (62.6\%). The mean age and median age of 837 patients were 19.92 and 16 years, respectively. The mortality rate gradually increased with the increase of the age at diagnosis (ACM: $50.6 \%$ vs. $45.3 \%$ vs. $25.7 \%, \mathrm{P}<0.001$; ESSM: $44.0 \%$ vs. $43.0 \%$ vs. $25.1 \%, \mathrm{P}<0.001$ ). Married patients' mortality was significantly higher than unmarried patients (ACM: $53.2 \%$ vs. $31.2 \%, \mathrm{P}<0.001$; ESSM: $29.8 \%$ vs. $48.5 \%, \mathrm{P}<0.001$ ). CT combined surgery achieved the highest OS and ESSS. Observing clinical pathology data, the primary site of the tumor located in pelvic bones, sacrum coccyx and associated joints, which had the highest mortality (ACM: 45.3\%; ESSM: 43.9\%). The mortality of tumors classified as American Joint Committee on Cancer (AJCC) III-IV stage was significantly higher than that of AJCC IIA and AJCC IIB stage, and the mortality increased with the higher AJCC stage (ACM: $53.0 \%$ vs. $31.3 \%$ vs. $21.0 \%, \mathrm{P}<0.001$; ESSM: $51.2 \%$ vs. $30.1 \%$ vs. $18.6 \%, \mathrm{P}<0.001$ ). The mortality of T2-T3 stage was significantly higher than that of T0-T1 stage (ACM: 40.7\% vs. 27.0\%, $\mathrm{P}<0.001$; ESSM: $39.1 \%$ vs. $24.8 \%, \mathrm{P}<0.001$ ). N1 stage was significantly higher than $\mathrm{N} 0$ (ACM: $49.2 \%$ vs. $32.8 \%, \mathrm{P}=0.008$; ESSM: $49.2 \%$ vs. 30.7\%, $\mathrm{P}=0.002$ ). M1 stage was significantly higher than M0 stage (ACM: $56.8 \%$ vs. $25.5 \%, \mathrm{P}<0.001$; ESSM: $55.2 \%$ vs. $23.5 \%, \mathrm{P}<0.001)$. Compared with other treatments, patients who received CT and surgery had the lowest ACM (21.7\%) and ESSM (20.9\%), and the mean survival (59.90 \pm 39.24 months) and median survival (53 months) were the longest.

Conclusions: From the demographic and tumor pathology data, the older patients at the age of diagnosis, married, the primary sites in the pelvic bones, sacrum coccyx and associated joints, American Joint Committee on Cancer (AJCC) III-IV, T2-T3, N1 and M1 stage tumors are all prompted to patients' poor prognosis. Compared with CT, CT and RT, or CT and RT and surgery, ewing sarcoma patients receiving CT combined with surgery have the longest median survival, the lowest mortality, and the best prognosis.

Keywords: Ewing sarcoma; chemotherapy; radiotherapy; surgery; Surveillance, Epidemiology, and End Results (SEER) 
Submitted Nov 28, 2019. Accepted for publication Feb 04, 2020.

doi: $10.21037 /$ tcr.2020.02.08

View this article at: http://dx.doi.org/10.21037/tcr.2020.02.08

\section{Introduction}

Ewing sarcoma is a small round cell tumor of bone or soft tissue originating from the neuroectoderm (1). Aggressive and highly malignant are the main pathological features of the tumor (1). Mainly due to the translocation of chromosome 11 and chromosome 22, the ews-fli1 fusion gene was formed, which led to the formation of ewing sarcoma $(2,3)$. ES is the second common primary bone malignancy in children and adolescents. It is rare in adults and the incidence ratio is about 1.5:1 (4). In primary tumors, ewing sarcoma accounts for $6-8 \%$, and occurs in the pelvis and limbs. It is rare in the spine $(1,5)$. The disease has a high degree of malignancy, short course of disease, rapid metastasis, simple surgery, radiotherapy (RT), singleagent chemotherapy (CT), the effect is not very satisfactory, the vast majority of patients died within 2 years, 5 years survival rate does not exceed $10 \%(1,5)$.

In the past, surgery was the main measure to treat this disease (6). With the improvement of the efficacy of RT and CT and the countermeasures for the side effects caused by it, the number of patients treated with surgery alone is decreasing $(6,7)$. But so far, surgical amputation or removal is still one of the treatments for this disease. The principle of surgery was to completely remove the tumor to maximize effective local control, prevent and reduce tumor metastasis. Ewing sarcoma is extremely sensitive to RT and is the main treatment. Generally, a small dose (3,000-4,000 rad) is irradiated, which can rapidly reduce the tumor and reduce or disappear the local pain $(7,8)$. However, the long-term effect of simple RT is very poor. In terms of CT, the drugs currently considered effective for ewing sarcoma include cyclophosphamide, doxorubicin, dactinomycin, vincristine, and carban mustard (9). Because most of the disease occurs within 2 years, it is generally recommended that CT should last for 2 years. Combined with a variety of treatments, the disease-free survival rate of ewing sarcoma patients has risen from less than $20 \%$ to $70-75 \%$ (1).

To date, few clinical retrospective studies have compared the efficacy of combination therapy in patients with ewing sarcoma. In addition, the demographic and tumor pathology features are summarized to see if the above characteristics have changed in recent years. Therefore, this study aimed to investigate which combination of treatments can improve the prognosis of patients with ewing sarcoma and identify factors that influence the prognosis of patients.

\section{Methods}

\section{Data collection}

Surveillance, Epidemiology, and End Results (SEER) database covers about 28 percent of the population of the United States and collects data on cancer patients from 18 tumor registration centers. The latest data for the (1973-2016 varying) database released in November 2018 was obtained using SEER stat special software (version 8.3.5), and data acquisition was done in client-server mode. A total of 837 patients with ewing sarcoma in the United States diagnosed between January 1, 2004 and December 31, 2015. Exclusion criteria include: unknown survival time, vital status, American Joint Committee on Cancer (AJCC) stage and TNM stage.

\section{Inclusion codes and criteria}

The main end points of the study were overall survival (OS) and ewing sarcoma-specific survival (ESSS). In this study, we classified patients according to the following factors, such as age $(0-18,19-40,>40)$, gender (male, female), race (White, others), marital status (yes, no) and state (West, East, South, North).

For the tumor, The tumors were classified according to the main location (upper limb, scapula and long bone of related joints; lower limb and long bone of related joints; rib, sternum, clavicle and associated joints; pelvic bones, sacrum coccyx and associated joints; other), grade (I, II, III, IV, Unknown), AJCC (IIA, IIB, III-IV), T (T0-T1,T2T3), N (N0, N1) and M (M0, M1).

\section{Statistical analysis}

The $\chi^{2}$ test was used to compare the basic clinical features of the patients included in the study and whether ewing sarcoma patients received CT, RT, or surgery. KaplanMeier survival curves and log-rank test were used to analyze the OS and ESSS of each prognostic factor and categorical 


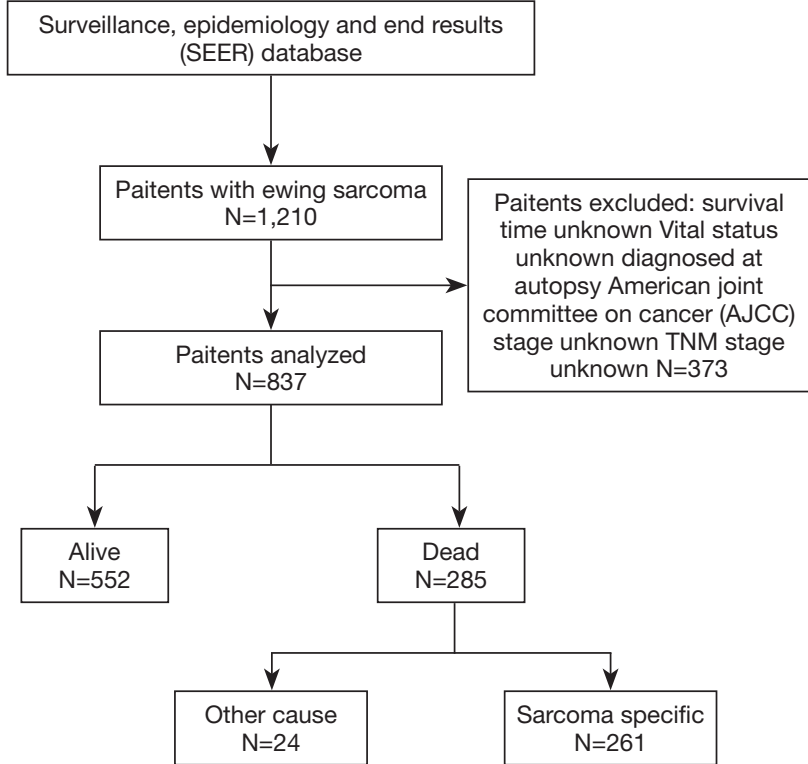

Figure 1 Flowchart of patients identification and selection.

variable. Multivariate Cox regression analysis was used to analyze all-cause mortality (ACM) and ewing sarcomaspecific mortality (ESSM) for each prognostic factor and categorical variable. Moreover, the hazard ratios (HR) and $95 \%$ confidence intervals (CI) for all strata of each factor are also calculated. The $\mathrm{P}$ value $<0.05$ is considered statistically significant. All statistical analysis is completed by Statistical package for the social sciences (version 23.0 USA).

\section{Results}

\section{Demographic and tumor pathological features of ewing sarcoma patients}

The specific screening process was shown in Figure 1. Between Jan 1, 2004 and Dec 31, 2015, 837 ewing sarcoma patients were included in this article. Patients receiving CT, RT or surgery were 804 (96.1\%), 414 (49.5\%), and 524 (62.6\%), respectively ( 1). From 2004 to 2015, the number of patients receiving CT was basically stable, and the proportion of patients receiving RT was also stable, while the proportion of patients undergoing surgery decreased to a certain extent, but there was no significant difference in the decline.

The mean age and median age of 837 patients were 19.92 and 16 years, respectively. The majority of the categorical variables in this study were $0-18$ years old $(60.3 \%)$, unmarried (87.0\%), white (89.2\%), male (62.2\%), diagnosed in the West $(49.6 \%)$ and the primary site in long bones of lower limb and associated joints (28.9\%). The categorical variables of age at diagnosis, primary site, tumour grade, AJCC stage and T stage were associated with CT. The categorical variables of state, primary site, AJCC stage, T stage and $\mathrm{M}$ stage were associated with RT. The categorical variable associated with surgery include age at diagnosis, primary site, tumor grade, AJCC stage and TNM stage. All variables had significant differences $\left(\chi^{2}\right.$ test: $\mathrm{P}$ value $\left.<0.05\right)$. The demographic and tumor pathological information of the patients was presented in Table 1 .

\section{The impact of different variables on ACM and ESSM}

Among all 873 patients, 285 (34.1\%) patients with allcause mortality, while 261 (31.2\%) died of ewing sarcoma (Figure 1, Table 2). Observing the demographic data, mortality was significantly higher in patients over 40 years compared with patients under 40 years, and the mortality rate gradually increased with the increase of the age at diagnosis (ACM: $50.6 \%$ vs. $45.3 \%$ vs. $25.7 \%, \mathrm{P}<0.001$; ESSM: $44.0 \%$ vs. $43.0 \%$ vs. $25.1 \%, \mathrm{P}<0.001)$. Married patients' mortality was significantly higher than unmarried patients (ACM: $53.2 \%$ vs. $31.2 \%, \mathrm{P}<0.001$; ESSM: $29.8 \%$ vs. $48.5 \%, \mathrm{P}<0.001)$. In addition, gender, ethnicity, and diagnostic areas had no significant effect on mortality.

Observing clinical pathology data, the primary site of the tumor located in pelvic bones, sacrum coccyx and associated joints, which had the highest mortality (ACM: 45.3\%; ESSM: 43.9\%). The mortality of tumors classified as AJCC III-IV stage was significantly higher than that of AJCC IIA and AJCC IIB stage, and the mortality increased with the higher AJCC stage (ACM: $53.0 \%$ vs. $31.3 \%$ vs. $21.0 \%$, $\mathrm{P}<0.001$; ESSM: $51.2 \%$ vs. $30.1 \%$ vs. $18.6 \%, \mathrm{P}<0.001)$. The mortality of T2-T3 stage was significantly higher than that of T0-T1 stage (ACM: $40.7 \%$ vs. $27.0 \%, \mathrm{P}<0.001$; ESSM: $39.1 \%$ vs. $24.8 \%, \mathrm{P}<0.001)$. $\mathrm{N} 1$ stage was significantly higher than N0 (ACM: $49.2 \%$ vs. $32.8 \%, \mathrm{P}=0.008$; ESSM: $49.2 \%$ vs. $30.7 \%, \mathrm{P}=0.002)$. M1 stage was significantly higher than $\mathrm{M} 0$ stage (ACM: $56.8 \%$ vs. $25.5 \%, \mathrm{P}<0.001$; ESSM: $55.2 \%$ vs. $23.5 \%, \mathrm{P}<0.001)$.

Observed treatment data showed that patients receiving CT had significantly improved ACM (33.2\% vs. $54.5 \%$, $\mathrm{P}<0.001)$, but ESSM was not statistically significant $(31.6 \%$ vs. 46.4\%, $\mathrm{P}=0.098)$. The ACM and ESSM of patients receiving $\mathrm{RT}$ was significantly higher (ACM: $40.6 \%$ vs. 27.7.\%, $\mathrm{P}<0.001$; ESSM: $38.3 \%$ vs. $26.1 \%, \mathrm{P}<0.001)$. 


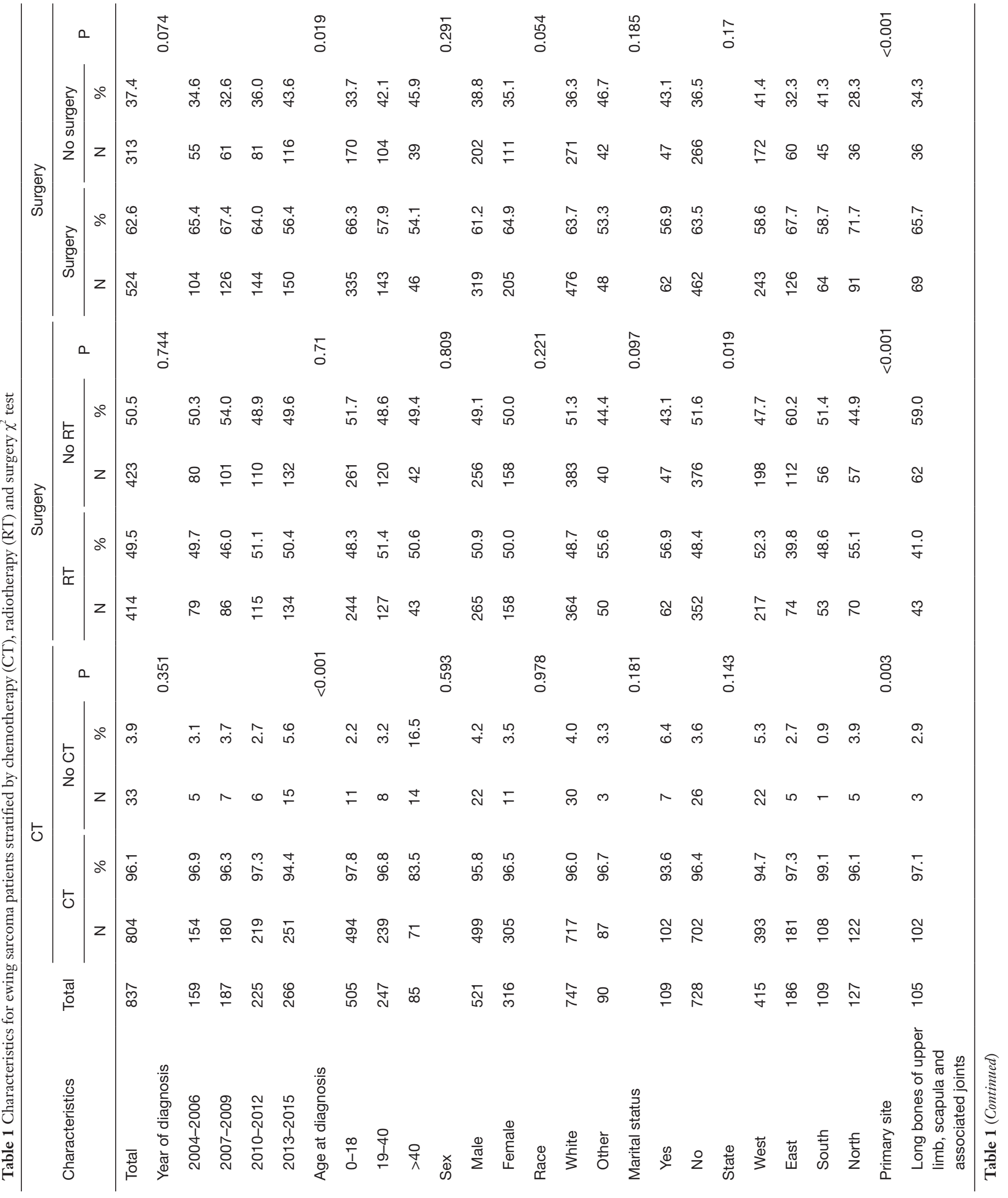




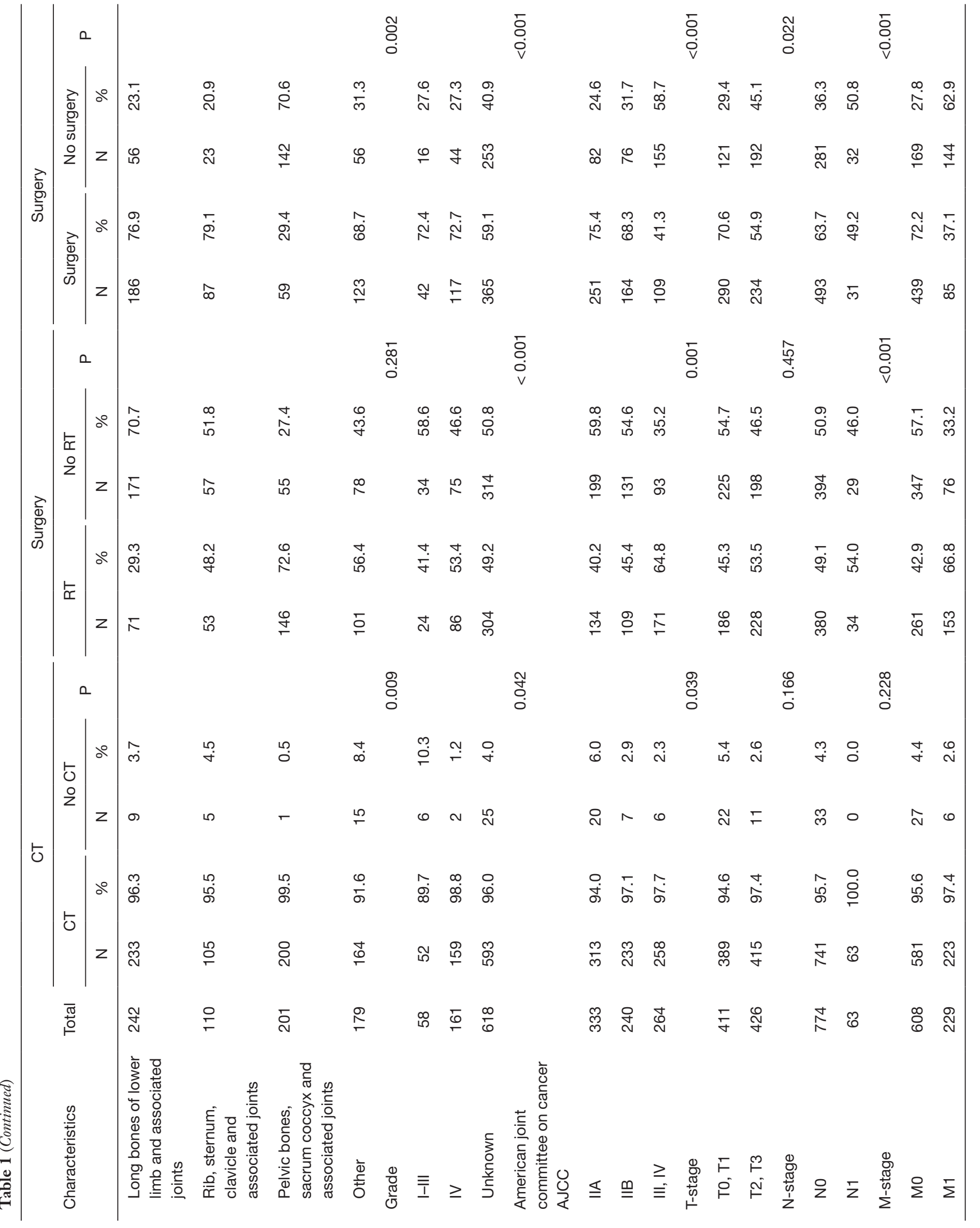


Table 2 Univariate survival analyses of ewing sarcoma patients according to various clinicopathological variables

\begin{tabular}{|c|c|c|c|c|c|c|c|c|c|c|}
\hline \multirow{2}{*}{ Characteristics } & \multicolumn{5}{|c|}{ All cause } & \multicolumn{5}{|c|}{ Ewing sarcoma-specific } \\
\hline & $\mathrm{N}$ & $\%$ & $\mathrm{~N}$ & $\%$ & $P$ & $\mathrm{~N}$ & $\%$ & $\mathrm{~N}$ & $\%$ & $\mathrm{P}$ \\
\hline Total & 285 & 34.1 & 552 & 65.9 & & 261 & 32.1 & 552 & 67.9 & \\
\hline Age at diagnosis & & & & & $<0.001$ & & & & & $<0.001$ \\
\hline $19-40$ & 112 & 45.3 & 135 & 54.7 & & 102 & 43.0 & 135 & 57.0 & \\
\hline$>40$ & 43 & 50.6 & 42 & 49.4 & & 33 & 44.0 & 42 & 56.0 & \\
\hline Sex & & & & & 0.149 & & & & & 0.072 \\
\hline Male & 187 & 35.9 & 334 & 64.1 & & 175 & 34.4 & 334 & 65.6 & \\
\hline White & 250 & 33.5 & 497 & 66.5 & & 229 & 31.5 & 497 & 68.5 & \\
\hline Other & 35 & 38.9 & 55 & 61.1 & & 32 & 36.8 & 55 & 63.2 & \\
\hline Marital status & & & & & $<0.001$ & & & & & $<0.001$ \\
\hline Yes & 58 & 53.2 & 51 & 46.8 & & 48 & 48.5 & 51 & 51.5 & \\
\hline No & 227 & 31.2 & 501 & 68.8 & & 213 & 29.8 & 501 & 70.2 & \\
\hline State & & & & & 0.203 & & & & & 0.33 \\
\hline West & 145 & 34.9 & 270 & 65.1 & & 132 & 32.8 & 270 & 67.2 & \\
\hline East & 56 & 30.1 & 130 & 69.9 & & 52 & 28.6 & 130 & 71.4 & \\
\hline $\begin{array}{l}\text { Long bones of lower limb and } \\
\text { associated joints }\end{array}$ & 73 & 30.2 & 169 & 69.8 & & 70 & 29.3 & 169 & 70.7 & \\
\hline $\begin{array}{l}\text { Rib, sternum, clavicle and } \\
\text { associated joints }\end{array}$ & 35 & 31.8 & 75 & 68.2 & & 28 & 27.2 & 75 & 72.8 & \\
\hline $\begin{array}{l}\text { Pelvic bones, sacrum coccyx and } \\
\text { associated joints }\end{array}$ & 91 & 45.3 & 110 & 54.7 & & 86 & 43.9 & 110 & 56.1 & \\
\hline Other & 59 & 33.0 & 120 & 67.0 & & 51 & 29.8 & 120 & 70.2 & \\
\hline Grade & & & & & 0.913 & & & & & 0.811 \\
\hline I-III & 21 & 36.2 & 37 & 63.8 & & 20 & 35.1 & 37 & 64.9 & \\
\hline IV & 57 & 35.4 & 104 & 64.6 & & 52 & 33.3 & 104 & 66.7 & \\
\hline Unknown & 207 & 33.5 & 411 & 66.5 & & 189 & 31.5 & 411 & 68.5 & \\
\hline
\end{tabular}

Table 2 (Continued) 
Table 2 (Continued)

\begin{tabular}{|c|c|c|c|c|c|c|c|c|c|c|}
\hline \multirow{2}{*}{ Characteristics } & \multicolumn{5}{|c|}{ All cause } & \multicolumn{5}{|c|}{ Ewing sarcoma-specific } \\
\hline & $\mathrm{N}$ & $\%$ & $\mathrm{~N}$ & $\%$ & $\mathrm{P}$ & $\mathrm{N}$ & $\%$ & $\mathrm{~N}$ & $\%$ & $\mathrm{P}$ \\
\hline $\begin{array}{l}\text { American joint committee on cancer } \\
\text { (AJCC) }\end{array}$ & & & & & $<0.001$ & & & & & $<0.001$ \\
\hline III, IV & 140 & 53.0 & 124 & 47.0 & & 130 & 51.2 & 124 & 48.8 & \\
\hline T-stage & & & & & $<0.001$ & & & & & $<0.001$ \\
\hline T0-T1 & 111 & 27.0 & 300 & 73.0 & & 99 & 24.8 & 300 & 75.2 & \\
\hline N1 & 31 & 49.2 & 32 & 50.8 & & 31 & 49.2 & 32 & 50.8 & \\
\hline M-stage & & & & & $<0.001$ & & & & & $<0.001$ \\
\hline MO & 155 & 25.5 & 453 & 74.5 & & 139 & 23.5 & 453 & 76.5 & \\
\hline M1 & 130 & 56.8 & 99 & 43.2 & & 122 & 55.2 & 99 & 44.8 & \\
\hline Chemotherapy (CT) & & & & & 0.011 & & & & & 0.098 \\
\hline Yes & 267 & 33.2 & 537 & 66.8 & & 248 & 31.6 & 537 & 68.4 & \\
\hline No & 18 & 54.5 & 15 & 45.5 & & 13 & 46.4 & 15 & 53.6 & \\
\hline No & 137 & 43.8 & 176 & 56.2 & & 126 & 41.7 & 176 & 58.3 & \\
\hline Treatment method & & & & & $<0.001$ & & & & & $<0.001$ \\
\hline No CT and no RT and no surgery & 6 & 50.0 & 6 & 50.0 & & 4 & 40.0 & 6 & 60.0 & \\
\hline CT & 38 & 42.2 & 52 & 57.8 & & 36 & 40.9 & 52 & 59.1 & \\
\hline RT & 2 & 66.7 & 1 & 33.3 & & 1 & 50.0 & 1 & 50.0 & \\
\hline Surgery & 6 & 50.0 & 6 & 50.0 & & 4 & 40.0 & 6 & 60.0 & \\
\hline $\mathrm{CT}$ and $\mathrm{RT}$ & 91 & 43.8 & 117 & 56.3 & & 85 & 42.1 & 117 & 57.9 & \\
\hline CT and surgery & 67 & 21.7 & 242 & 78.3 & & 64 & 20.9 & 242 & 79.1 & \\
\hline $\mathrm{RT}$ and surgery & 4 & 66.7 & 2 & 33.3 & & 4 & 66.7 & 2 & 33.3 & \\
\hline $\mathrm{CT}$ and RT and surgery & 71 & 36.0 & 126 & 64.0 & & 63 & 33.3 & 126 & 66.7 & \\
\hline
\end{tabular}


Surgery improved ACM (28.2\% vs. $43.8 \%, \mathrm{P}<0.001)$ and ESSM $(26.4 \%$ vs. $41.7 \%, \mathrm{P}<0.001)$. CT combined surgery achieved the lowest ACM (21.7\%) and ESSM (20.9\%).

\section{Survival}

We plotted Kaplan-Meier survival curves based on patient OS and ESSS for some factors that were statistically different in Table 2, including age at diagnosis, marital status, primary site, AJCC stage, TNM stage and treatment method (Figure 2).

The median survival and survival month are shown in Table 3. Overall median survival was 42.0 months. Patients with a diagnosis of $0-18$ years of age had significantly better survival months $(57.54 \pm 39.83$ vs. $46.81 \pm 37.03$ vs. $39.05 \pm 35.97$ months) and median survival (47 vs. 36 vs. 24 months). The number of months of unmarried patients was significantly longer $(54.35 \pm 39.69 v s .40 .14 \pm$ 32.95 months) and median survival (43 vs. 28 months). Among the primary sites, the longest survival months were

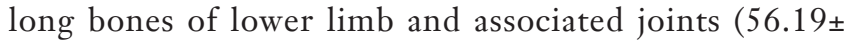
39.17 months), while the highest median survival time was rib, sternum, clavicle and associated joints (51 months). In the AJCC staging, patients with stage IIA had the longest survival $(61.18 \pm 41.49$ vs. $57.36 \pm 39.24$ vs. $37.13 \pm$ 30.75 months) and median survival (51 vs. $47 v s .28$ months). In TNM staging, T0-T1 stage, N0 stage and M0 stage were significantly longer $(56.82 \pm 40.81$ vs. $48.33 \pm 37.05$; $53.62 \pm 39.48$ vs. $38.76 \pm 32.04 ; 59.21 \pm 40.30$ vs. $34.68 \pm$ 29.27 months, respectively) and median survival (46 vs. 37 months; 43 vs. 32 months; 49 vs. 26 months, respectively).

Patients with CT or surgery have achieved the longest survival $(53.43 \pm 39.10$ vs. $29.88 \pm 33.75$ months; $59.95 \pm 39.86$ vs. $41.70 \pm 35.45$ months) and median survival (43 vs. 18 months; 49 vs. 30 months). The mean survival (49.89 \pm 37.97 vs. $55.04 \pm 40.16$ months) and median survival (37 vs. 47 months) of patients receiving RT decreased. CT combined surgery achieved the longest mean survival (59.90 \pm 39.24 months) and median survival (53 months) (Table 3). Patients who underwent CT or received CT combined with RT had close median survival (32 vs. 30 months).

\section{Multivariate Cox regression of prognostic factors in ewing sarcoma patients}

Multivariate Cox regression analysis of factors such as age, race, marital status, sex, primary site, state, grade, AJCC, TNM stage and treatment methods (Table 4). Using age at diagnosis $0-18$ years as a reference, patients with 1940 years and $>40$ years had increased risk of ACM ACM $(19-40$ years, HR $=1.793 ;>40$ years, HR $=2.179)$ and ESSM (19-40 years, HR $=1.714 ;>40$ years, HR $=1.866$ ). Using married as a reference, unmarried patients had decreased risk of ACM (unmarried, HR $=0.624$ ) and ESSM (unmarried, HR =0.869). Using AJCC stage IIA as a reference, IIB and III-IV stage patients had increased risk of ACM (IIB, HR = 1.758; III-IV, HR =1.189) and ESSM (IIB, HR =1.967; III-IV, HR =1.047).

Using received CT as a reference, unreceived CT patients had increased risk of ACM (no CT, HR =3.120) and ESSM (no CT, HR =2.685). Using received surgery as a reference, unreceived surgery patients had increased risk of ACM (no surgery, HR =1.305) and ESSM (no surgery, HR $=1.283$ ). Using received RT as a reference, unreceived RT patients had decreased risk of ACM (no RT, HR $=0.870$ ) and ESSM (no RT, HR =0.878). Using only CT treatment as a reference, CT combined surgery had achieved the best prognosis (ACM: HR $=0.391$; ESSM: HR $=0.393$ ), CT combined with RT and surgery also achieved a good prognosis (ACM: HR =0.652; ESSM: HR $=0.620$ ).

\section{Discussion}

Ewing sarcoma is mainly found in bones and muscles, and is also found in soft tissues (10). The disease is more common in men, and there are differences in species, which are common in white people, and Asians and Africans are rare. Early ewing sarcoma has a single treatment and a poor prognosis (11). In recent years, with the deepening of research and the improvement of medical treatment methods, the OS rate of ewing sarcoma patients has been significantly improved (12).

CT is considered to be a widely accepted treatment, which is well documented in our study, regardless of the number of patients receiving CT $(6,9,13)$. Still from the perspective of survival rate, CT is undoubtedly the best solution. Current research focuses on the choice of CT protocol (14-18). Bacci et al. (19) retrospectively analyzed the situation of 579 patients with ewing sarcoma admitted from 1972 to 1998 . All patients underwent CT. Not only the number of CT drugs was different, but also the time distribution difference in the choice of chemotherapy regimen. In this study, it was found that with the increase in the number of chemotherapy drugs 

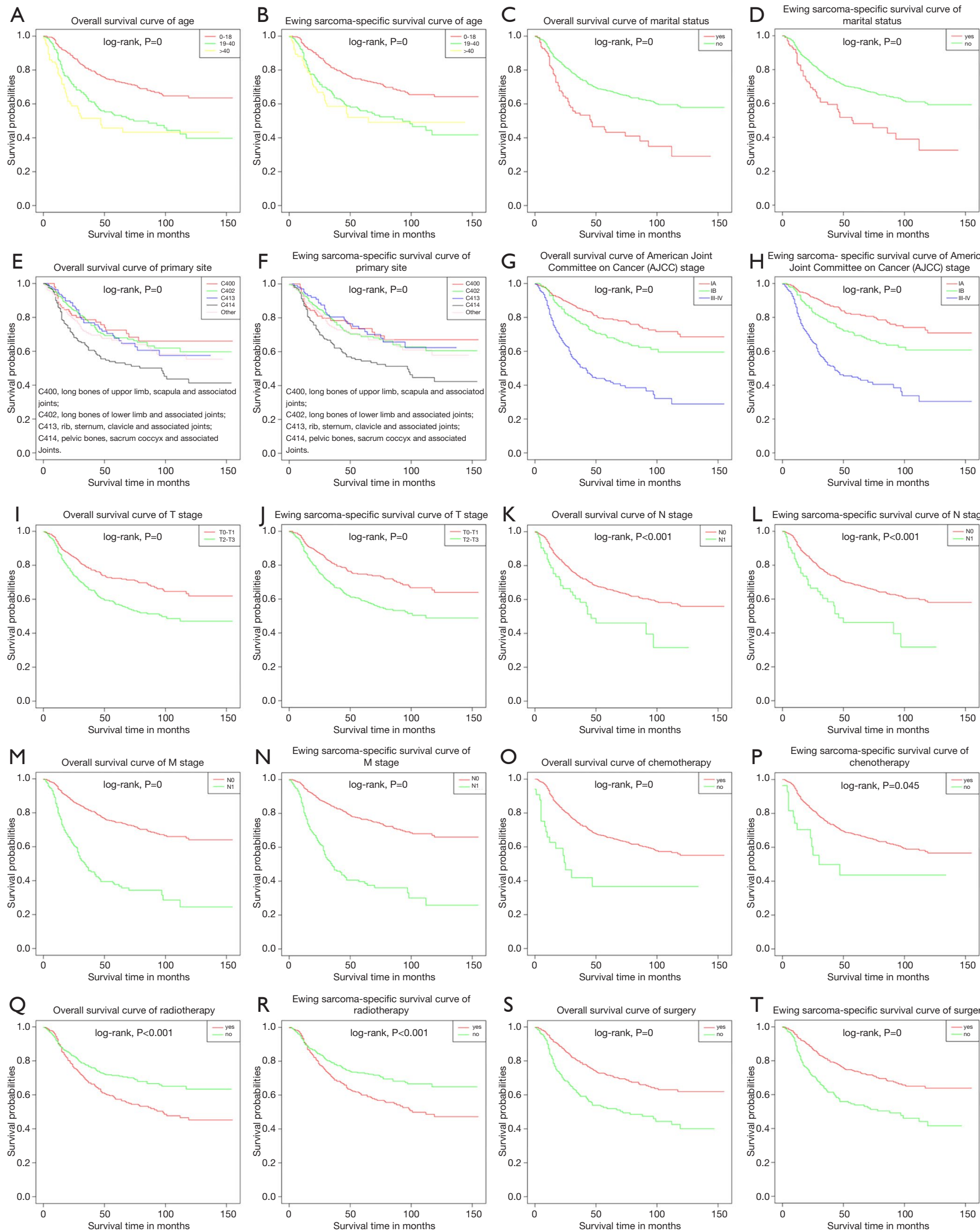

Ewing sarcoma- specific survival curve of America
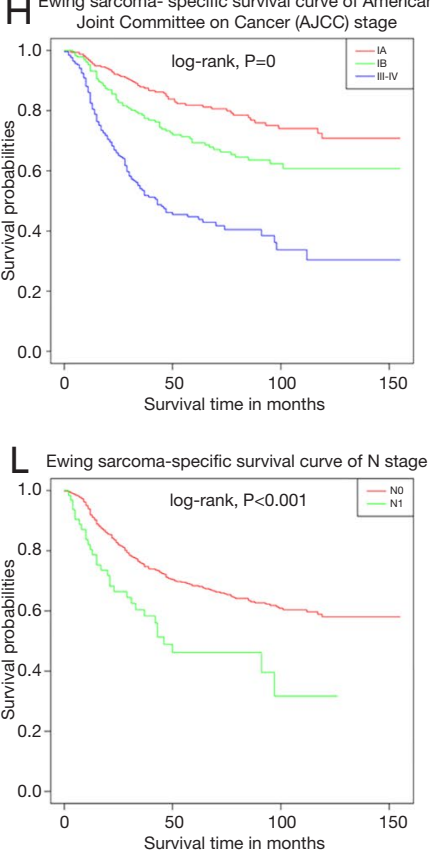

P Ewing sarcoma-specific survival curve of

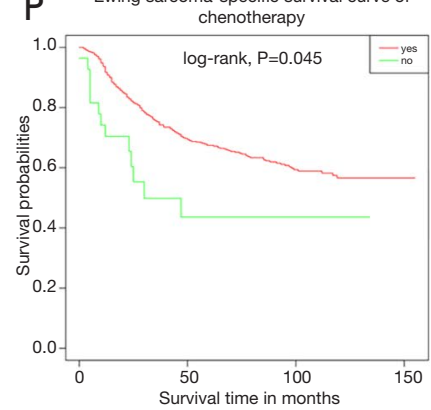

T Ewing sarcoma-specific survival curve of surgery

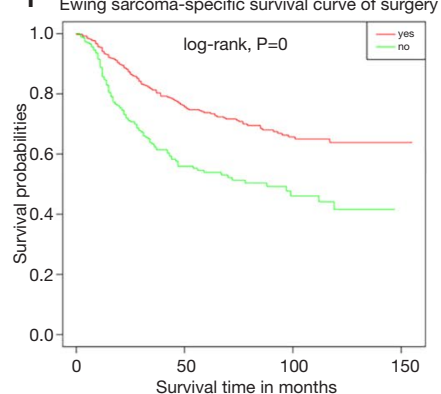



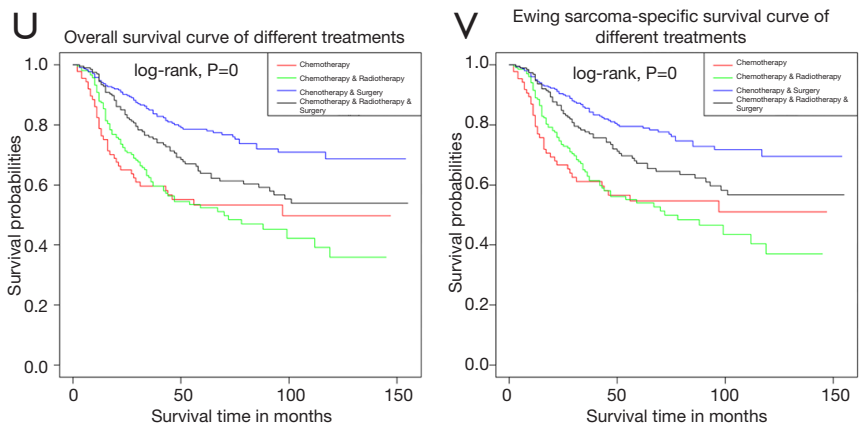

Figure 2 Survival curves in ewing sarcoma patients according to different treatments and other factors.

Table 3 Median and mean survival months of ewing sarcoma patients

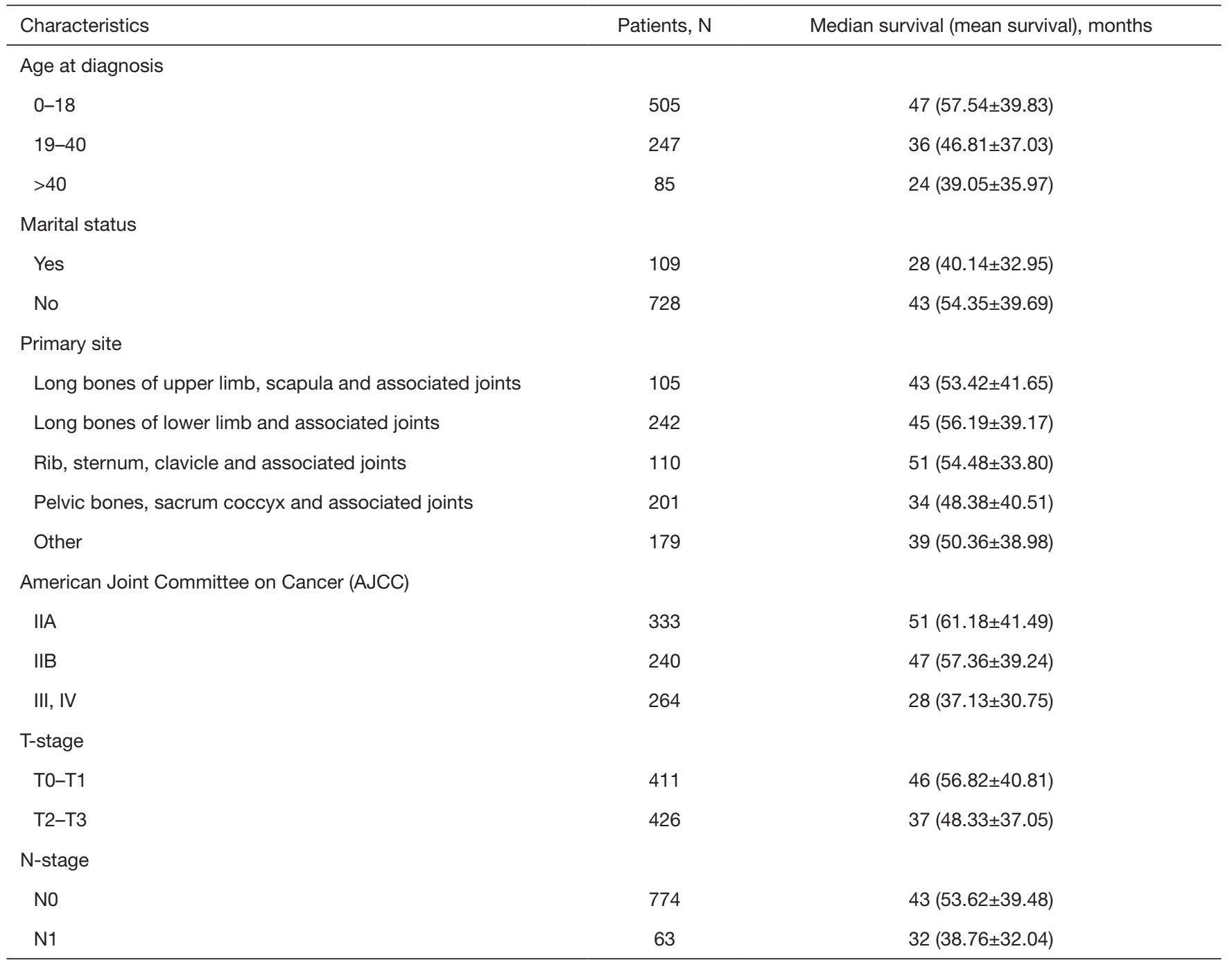

Table 3 (Continued) 
Table 3 (Continued)

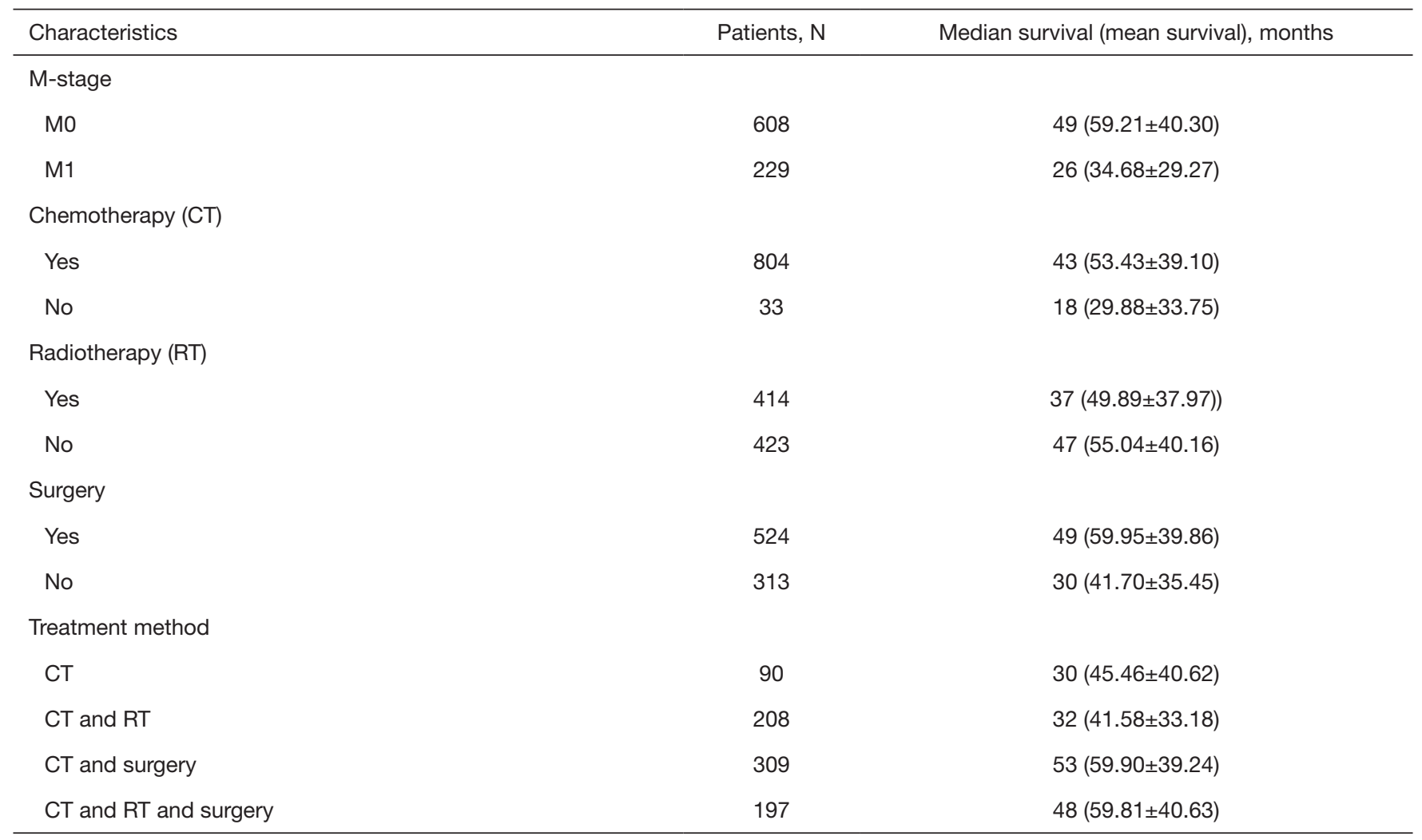

Table 4 Multivariate Cox regression analysis for all-cause mortality and ewing sarcoma-specific mortality in patients with different treatments and other factors

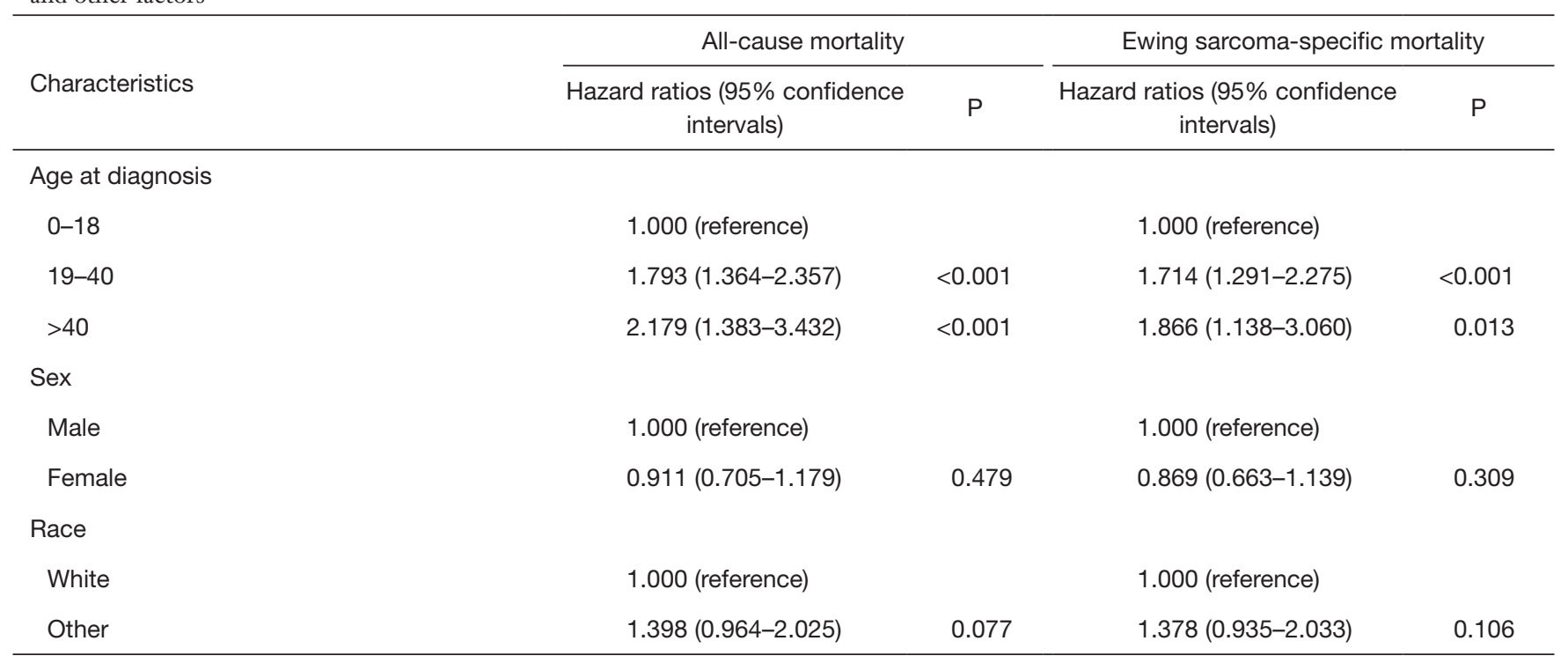

Table 4 (Continued) 
Table 4 (Continued)

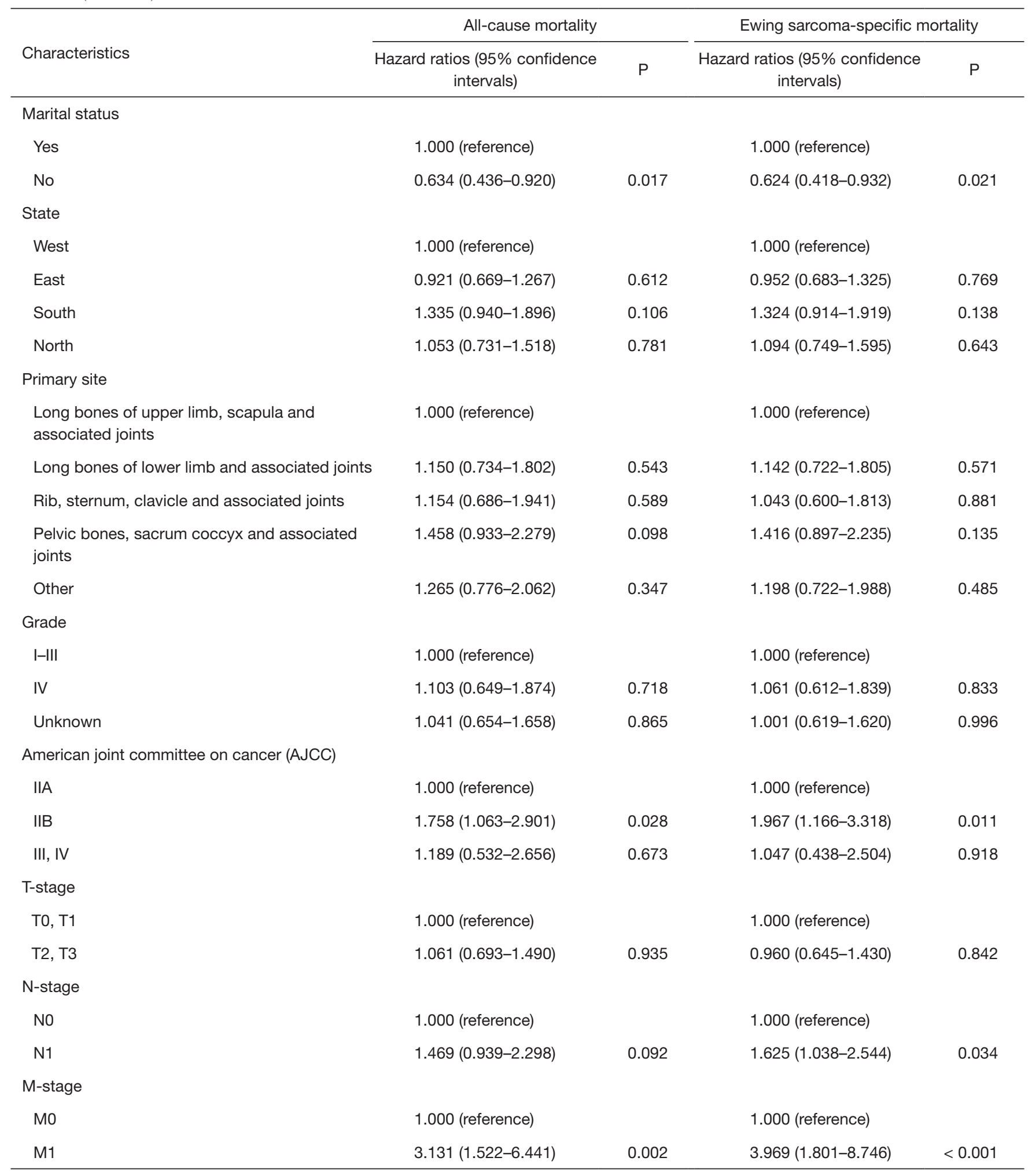

Table 4 (Continued) 
Table 4 (Continued)

\begin{tabular}{|c|c|c|c|c|}
\hline Characteristics & \multicolumn{2}{|l|}{ All-cause mortality } & \multicolumn{2}{|c|}{ Ewing sarcoma-specific mortality } \\
\hline Yes & 1.000 (reference) & & 1.000 (reference) & \\
\hline Yes & 1.000 (reference) & & 1.000 (reference) & \\
\hline No & $0.870(0.672-1.126)$ & 0.29 & $0.878(0.671-1.150)$ & 0.346 \\
\hline \multicolumn{5}{|l|}{ Surgery } \\
\hline CT & 1.000 (reference) & & 1.000 (reference) & \\
\hline CT and RT & $1.034(0.707-1.511)$ & 0.864 & $1.023(0.693-1.513)$ & 0.908 \\
\hline CT and surgery & $0.391(0.263-0.583)$ & $<0.001$ & $0.393(0.261-0.591)$ & $<0.001$ \\
\hline $\mathrm{CT}$ and RT and surgery & $0.652(0.439-0.966)$ & 0.033 & $0.620(0.412-0.935)$ & 0.022 \\
\hline
\end{tabular}

and the continuous update of chemotherapy regimens, 5 -year disease-free survival increased, which means that researchers have deepened their understanding of ewing sarcoma, and targeted treatment is widely used. Abou Ali et al. (17) reviewed 42 ewing sarcoma patients admitted to the institution from 1999 to 2012 . All patients underwent CT, and the CT regimen was well tolerated. A research cooperation group in Brazil to determine the effect of alternating VDC (vincristine, doxorubicin, cyclophosphamide) with ICE (ifosfamide, carboplatin and etoposide) as a first-line treatment for newly diagnosed Ewing sarcoma family tumors (ESFT) patients, institutional patients with 0-30 years of histologically confirmed ESFT were selected in the study and found that carboplatin did not appear to increase the prognosis of patients identified as high risk, on the contrary, the toxicity was more significant. The group believes that the addition of carboplatin can produce significant toxicity and has no significant improvement in prognosis (20). A large clinical trial comparing the efficacy of cyclophosphamide or ifosfamide in ewing sarcoma patients who were identified as standard risk, which suggests that cyclophosphamide can replace the standard risk of ewing sarcoma with ifosfamide.
However, compared with VAI (vincristine, dactinomycin, and ifosfamide), there are still some uncertainties in the non-inferiority of VAC (vincristine, dactinomycin, and cyclophosphamide), and volunteers are still needed to conduct long-term renal and gonadal toxicity studies (21).

Local treatment is also an important step, surgery and radiotherapy are currently widely accepted local treatments (22). The effective resection of the primary lesion by surgery is considered to be an important factor affecting the prognosis. However, sometimes the patient's own condition or disease cannot be operated, and RT is needed to treat the local part. Casey et al. (8) performed RT on 22 patients with ewing sarcoma bone metastases between 1999 and 2013. The study found that radiotherapy for the metastatic site and the primary site can improve the survival rate of patients. Similarly, it is clear that the therapeutic dose range of the primary site of treatment can be applied to the treatment of the metastatic site. European Ewing Sarcoma Research Group reported an observational study in 2016 to determine whether the presence of postoperative RT is significant in the local standard risk ewing sarcoma (7). The study included a total of 599 patients, of whom 142 (24\%) received postoperative RT (median dose: 45 Grays), 
and received surgery combined with RT had a significantly lower local recurrence rate than simple surgery $(\mathrm{HR}=0.43)$. RT appears to be an effective local treatment, especially when surgery cannot be completely removed or CT cannot effectively reduce tumor volume. One of the challenges of using RT to treat pediatric ewing sarcoma, the use of highRT doses, while achieving good therapeutic results, can have a devastating effect on the surrounding tissue. In order to balance this relationship, Talleur et al. (23) suggested adopting protective measures and dose control for larger tumors to solve the radiotherapy dilemma of pediatric ewing sarcoma, and confirmed the method to increase the dose of radiation by reviewing 45 patients. A good prognosis is achieved without increasing the risk at the standard dose.

In our study, age and gender were also considered to be important factors influencing the prognosis of ewing sarcoma patients. As the age increased, the risk of death increased. In addition, male mortality was higher than female. In addition to being an independent prognostic factor, treatment options are also closely related to age and gender $(11,24,25)$. Paioli et al. (26) studied the relationship between CT-related toxicity and gender and age in nonmetastatic ewing sarcoma. This study found that the hematological toxicity of CT drugs did not differ between children and adults; in women with ewing sarcoma, CTrelated blood. The incidence of learning toxicity is higher. National Cancer Registry of Australia has reported that young male ewing sarcoma patients aged 15 to 30 years after CT have a higher mortality rate than children (24).

We demonstrate that CT combined surgery or CT combined with RT can significantly improve prognosis compared with simple CT. Compared with CT alone, CT combined with RT may not help to increase median survival (30 vs. 32 months), also does not help to reduce ACM (HR =1.034) and ESSM (HR =1.023). This study found that the increase in age, primary site in pelvic bones, sacrum coccyx and associated joints, AJCC stage rise and TNM stage rise were risk factors for ewing sarcoma patients with unsatisfactory prognosis. For the treatment of ewing sarcoma patients, we recommend to develop a treatment plan based on individual differences based on comprehensive treatment.

\section{Limitations}

This study is based on a retrospective study conducted by the SEER database. Due to the limitations of the data included in the database itself, more detailed patient information is not available. We are unable to obtain specific indicators such as lactate dehydrogenase (LDH), whether it is neoadjuvant CT and standard CT, the number of RT, and the specific method of each irradiation dose and surgical treatment, which limits our further evaluation. The relationship between treatment and prognosis. In addition, this article does not summarize the transfer situation. After we conducted preliminary statistics, the database ewing sarcoma patient transfer situation could not get complete information. In addition, due to the limited overall sample size, the number of metastases patients could not reach our ideal number. This limits our detailed analysis of metastatic cases.

\section{Conclusions}

From the demographic and tumor pathology data, the older the patients at the age of diagnosis, married, the primary sites in the pelvic bones, sacrum coccyx and associated joints, AJCC III-IV, T2-T3, N1 and M1 stage tumors are all prompted to patients' poor prognosis. Multiple methods of integrated therapy have become the consensus of most cancer treatments. This study includes four treatments, CT combined surgery is the best treatment option, ewing sarcoma patients can get the longest median survival and the highest survival rate. Compared with CT, CT and RT, or CT and RT and surgery, ewing sarcoma patients receiving CT combined with surgery have the longest median survival, the lowest mortality, and the best prognosis.

\section{Acknowledgments}

K Hua: I would like to express my special thanks to my partners for the encouragement and support they gave me during my study. Thanks to my wife, Mrs Sun, for her support for my life and research.

Funding: None.

\section{Footnote}

Conflicts of Interest: Both authors have completed the ICMJE uniform disclosure form (available at http://dx.doi. org/10.21037/tcr.2020.02.08). The authors have no conflicts of interest to declare.

Ethical Statement: The authors are accountable for all aspects of the work in ensuring that questions related 
to the accuracy or integrity of any part of the work are appropriately investigated and resolved.

Open Access Statement: This is an Open Access article distributed in accordance with the Creative Commons Attribution-NonCommercial-NoDerivs 4.0 International License (CC BY-NC-ND 4.0), which permits the noncommercial replication and distribution of the article with the strict proviso that no changes or edits are made and the original work is properly cited (including links to both the formal publication through the relevant DOI and the license). See: https://creativecommons.org/licenses/by-nc-nd/4.0/.

\section{References}

1. Berger GK, Nisson PL, James WS, et al. Outcomes in different age groups with primary Ewing sarcoma of the spine: a systematic review of the literature. J Neurosurg Spine 2019;15:1-10.

2. Gorthi A, Romero JC, Loranc E, et al. EWS-FLI1 increases transcription to cause R-Loops and block BRCA1 repair in Ewing sarcoma. Nature 2018;555:387-91.

3. Allegretti M, Casini B, Mandoj C, et al. Precision diagnostics of Ewing's sarcoma by liquid biopsy: circulating EWS-FLI1 fusion transcripts. Ther Adv Med Oncol 2018;10:1758835918774337.

4. Pessetto ZY, Chen B, Alturkmani H, et al. In silico and in vitro drug screening identifies new therapeutic approaches for Ewing sarcoma. Oncotarget 2017;8:4079-4095.

5. Balamuth NJ, Womer RB. Ewing's sarcoma. Lancet Oncol 2010;11:184-92.

6. Theisen ER, Pishas KI, Saund RS, et al. Therapeutic opportunities in Ewing sarcoma: EWS-FLI inhibition via LSD1 targeting. Oncotarget 2016;7:17616-30.

7. Foulon S, Brennan B, Gaspar N, et al. Can postoperative radiotherapy be omitted in localised standard-risk Ewing sarcoma? An observational study of the Euro-E.W.I.N.G group. Eur J Cancer 2016;61:128-36.

8. Casey DL, Wexler LH, Meyers PA, et al. Radiation for bone metastases in Ewing sarcoma and rhabdomyosarcoma. Pediatr Blood Cancer 2015;62:445-9.

9. Ferrari S, Bertoni F, Palmerini E, et al. Predictive Factors of Histologic Response to Primary Chemotherapy in Patients With Ewing Sarcoma. J Pediatr Hematol Oncol 2007;29:364-8.

10. Biswas B, Bakhshi S. Management of Ewing sarcoma family of tumors: Current scenario and unmet need. World J Orthop 2016;7:527-38.
11. Worch J, Matthay KK, Neuhaus J, et al. Ethnic and racial differences in patients with Ewing sarcoma. Cancer, 2010;116:983-8.

12. Wan W, Lou $Y, H u Z$, et al. Factors affecting survival outcomes of patients with non-metastatic Ewing's sarcoma family tumors in the spine: a retrospective analysis of 63 patients in a single center. J Neurooncol 2017;131:313-20.

13. Rasper M, Jabar S, Ranft A, et al. The value of highdose chemotherapy in patients with first relapsed Ewing sarcoma. Pediatr Blood Cancer 2014;61:1382-6.

14. Choy E, Butrynski J, Harmon D, et al. Phase II study of olaparib in patients with refractory Ewing sarcoma following failure of standard chemotherapy. BMC Cancer 2014;14:813.

15. Yoon JH, Kwon MM, Park HJ, et al. A study of docetaxel and irinotecan in children and young adults with recurrent or refractory Ewing sarcoma family of tumors. BMC Cancer 2014;14:622.

16. Paulussen M, Ahrens S, Dunst J, et al. Localized Ewing Tumor of Bone: Final Results of the Cooperative Ewing's Sarcoma Study CESS 86. J Clin Oncol 2001;19:1818-29.

17. Abou Ali B, Nader R, Tamim H, et al. Outcome of Ewing sarcoma in a multidisciplinary setting in Lebanon. Pediatr Blood Cancer 2014;61:1472-5.

18. Friedman DN, Chastain K, Chou JF, et al. Morbidity and mortality after treatment of Ewing sarcoma: A single-institution experience. Pediatr Blood Cancer 2017;64:1-10.

19. Bacci G, Longhi A, Ferrari S, et al. Prognostic factors in non-metastatic Ewing's sarcoma tumor of bone: an analysis of 579 patients treated at a single institution with adjuvant or neoadjuvant chemotherapy between 1972 and 1998. Acta Oncol 2006;45:469-75.

20. Brunetto AL, Castillo LA, Petrilli AS, et al. Carboplatin in the treatment of Ewing sarcoma: Results of the first Brazilian collaborative study group for Ewing sarcoma family tumors-EWING1. Pediatr Blood Cancer 2015;62:1747-53.

21. Le Deley MC, Paulussen M, Lewis I, et al. Cyclophosphamide compared with ifosfamide in consolidation treatment of standard-risk Ewing sarcoma: results of the randomized noninferiority EuroEWING99-R1 trial. J Clin Oncol 2014;32:2440-8.

22. Mirzaei L, Kaal SE, Schreuder HW, et al. The Neurological Compromised Spine Due to Ewing Sarcoma. What First: Surgery or Chemotherapy? Therapy, Survival, and Neurological Outcome of 15 Cases With Primary 
Ewing Sarcoma of the Vertebral Column. Neurosurgery 2015;77:718-24.

23. Talleur AC, Navid F, Spunt SL, et al. Limited Margin Radiation Therapy for Children and Young Adults With Ewing Sarcoma Achieves High Rates of Local Tumor Control. Int J Radiat Oncol Biol Phys 2016;96:119-26.

24. Khamly KK, Thursfield VJ, Fay M, et al. Gender-specific activity of chemotherapy correlates with outcomes in chemosensitive cancers of young adulthood. Int J Cancer

Cite this article as: Hua $\mathrm{K}, \mathrm{Hu} \mathrm{Y}$. Effects of different treatments and other factors on the prognosis of patients with ewing sarcoma. Transl Cancer Res 2020;9(3):1931-1946. doi: 10.21037/tcr.2020.02.08
2009;125:426-31.

25. van den Berg H, Paulussen M, Le Teuff G, et al. Impact of gender on efficacy and acute toxicity of alkylating agent-based chemotherapy in Ewing sarcoma: secondary analysis of the Euro-Ewing99-R1 trial. Eur J Cancer 2015;51:2453-64.

26. Paioli A, Luksch R, Fagioli F, et al. Chemotherapy-related toxicity in patients with non-metastatic Ewing sarcoma: influence of sex and age. J Chemother 2014;26:49-56. 